\title{
(3) Double Digestion and Dephosphorylation of Plasmid
}

Igem Dusseldorf ${ }^{1}$

${ }^{1}$ Heinrich-Heine Universität Düsseldorf

Igem Dusseldorf

\section{open $\partial$ ACCESS}

\section{DOI:}

dx.doi.org/10.17504/protocol s.io. 79 phr5n

Protocol Citation: Igem Dusseldorf 2019. Double Digestion and

Dephosphorylation of Plasmid. protocols.io

https://dx.doi.org/10.17504/p rotocols. io. $79 \mathrm{phr} 5 \mathrm{n}$

License: This is an open access protocol distributed under the terms of the Creative Commons Attribution License, which permits unrestricted use, distribution, and reproduction in any medium, provided the original author and source are credited

Protocol status: Working We use this protocol and it's working

Created: Oct 15, 2019

Last Modified: Oct 18, 2019

PROTOCOL integer ID:

28687

1

Mix the following components gently: 


\begin{tabular}{|c|c|}
\hline $\begin{array}{l}\text { Comp } \\
\text { onent } \\
s\end{array}$ & $\mathrm{ng} / \mu \mathrm{L}$ \\
\hline $\begin{array}{l}\text { Plasm } \\
\text { id } \\
\text { DNA } \\
\text { Tube } \\
\text { X }\end{array}$ & \\
\hline $\begin{array}{l}\text { Comp } \\
\text { onent }\end{array}$ & \begin{tabular}{|l} 
Volu \\
me \\
$(\mu \mathrm{L})$
\end{tabular} \\
\hline $\begin{array}{l}\text { Steril } \\
\text { e } \\
\text { MilliQ } \\
\text { Water }\end{array}$ & \begin{tabular}{|l|} 
Fill up \\
to \\
30.0 \\
$\mu \mathrm{l}$
\end{tabular} \\
\hline $\begin{array}{l}10 x \\
\text { FastD } \\
\text { igest } \\
\text { Buffer }\end{array}$ & 3.0 \\
\hline $\begin{array}{l}\text { Plasm } \\
\text { id } \\
\text { DNA }\end{array}$ & $\begin{array}{l}\text { Total } \\
\text { ng of } \\
\text { DNA/ } \\
\text { Plasm } \\
\text { id } \\
\text { DNA } \\
\text { conce } \\
\text { ntrati } \\
\text { on } \\
\text { ng/ } \mu l \\
\end{array}$ \\
\hline $\begin{array}{l}\text { FastD } \\
\text { igest } \\
\text { Enzy } \\
\text { me } 1\end{array}$ & 1.0 \\
\hline $\begin{array}{l}\text { FastD } \\
\text { igest } \\
\text { Enzy } \\
\text { me } 2 \\
\end{array}$ & 1.0 \\
\hline $\begin{array}{l}\text { FastA } \\
\text { P } \\
\text { Alkali } \\
\text { ne } \\
\text { Phosp } \\
\text { hatas } \\
\text { e }\end{array}$ & 1.0 \\
\hline $\begin{array}{l}\text { Total } \\
\text { Volu } \\
\text { me }\end{array}$ & 30.0 \\
\hline $\begin{array}{l}\text { Total } \\
\text { ng of } \\
\text { DNA }\end{array}$ & $\begin{array}{l}1000 . \\
0\end{array}$ \\
\hline
\end{tabular}

2 Incubate at enzyme suitable conditions 00:30:00- $01: 00: 00$ and temperature 
Note

Find out suitable conditions on website of particular science company

3 Inactivate the enzymes at suitable conditions and temperature

Note

Find out suitable conditions on website of particular science company

4 Run gel at $80-150 \mathrm{~V}$ until the dye line is approximately $75-80 \%$ of the way down the gel. A typical run time is about $1-1.5$ hours, depending on the gel concentration and voltage.

$5 \quad$ Cut out digested band ( $150 \mathrm{mg}$ ) and transfer to pre-weighed tube. Check weight.

6 Purify the band 